\title{
Serial electrocardiographic changes in healthy and stressed neonates
}

\author{
R JEDEIKIN, A PRIMHAK, A T SHENNAN, P R SWYER, AND R D ROWE \\ Department of Pediatrics, The Hospital for Sick Children, Toronto, and the Department of Neonatology, \\ Women's College Hospital, Toronto
}

SUMMARY Serial changes in T-wave vector and polarity were assessed in 162 electrocardiograms, 117 from 44 healthy term neonates and 45 from 17 stressed neonates. Records were taken at 5 to 8 hours, 24 to 33 hours, and 71 to 96 hours after birth. Sequential changes in both T-wave amplitude and frontal and horizontal axes were found in both groups. A lag period was noted between healthy and stressed infants when comparing changes in $\mathrm{T}$-wave amplitude, with greater flattening of $\mathrm{T}$-waves for longer periods of time after birth in the stressed group. The normal changes in $\mathrm{T}$-wave axis over time in the horizontal and frontal planes showed a similar lag in the stressed group. Alterations of T-wave amplitude and axis alone may be markers of myocardial ischaemia in neonates but are only reliable signs after the first 24 hours of life.

Sequential changes in T-wave polarity occur in healthy term newborns in the first few days of life ${ }^{1-5}$ but a satisfactory explanation for these relatively consistent electrocardiographic (ECG) findings has not yet been given. There has been reluctance to consider that these changes may reflect an ischaemia during haemodynamic adjustments after birth, despite the fact that several investigators have described related abnormalities in the ECGs of term infants with cardiorespiratory distress secondary to birth asphyxia. ${ }^{6-10} \mathrm{We}$ examined serial changes after birth in the ECGs of both normal and distressed infants to determine whether there were differences between the 2 groups.

\section{Patients and methods}

Patients. Criteria were established to identify 2 different groups of newborn infants.

\section{Normal healthy infants}

Babies were considered healthy if they satisfied all the following criteria:

1) Uncomplicated labour and delivery.

2) Gestational age of 36 to 42 weeks.

3) Normal newborn physical examination.

4) Uneventful hospital course extending to the time of discharge.

5) Structurally normal heart.

Infants born by caesarean section for either maternal or fetal distress and infants with extracardiac malformations were excluded. Forty four healthy term infants born at the Woman's College Hospital (WCH), Toronto, satisfied these criteria. They included 33 infants born by vaginal delivery and 11 by elective caesarean section.

\section{Stressed infants}

Babies who met all the following criteria were considered to be stressed:

1) Gestational age of 36 to 42 weeks.

2) Five minute Apgar score of $\leqslant 6$ (birth asphyxia).

3) Respiratory distress requiring transfer to an intensive care unit at or shortly after birth (transient tachypnoea, meconium aspiration).

4) Structurally normal heart.

Infants with extracardiac malformation were excluded. Seventeen babies satisfied these criteria and were admitted soon after birth to the neonatal intensive care unit at the Hospital for Sick Children (HSC), Toronto.

Methods. Serial ECGs were obtained from both groups of infants over approximately 4 days. The study was approved by the ethical committees of both hospitals and by the parents.

The ECG included all standard leads and precordial leads from V1 to V6. Records were taken at 5 to 8 hours, 24 to 33 hours, and 71 to 96 hours after birth. The tracings recorded at WCH were obtained from a 
direct writing Burdick Model EKSA and were done by one of us (R J) or by a trained nurse. Those performed at HSC were done by experienced ECG technicians using a direct writing Hewlett Packard Model 1500-B. The paper speeds were $25 \mathrm{~mm} / \mathrm{second}$ in both models, with a single channel recording. Sensitivity was $1 \mathrm{mV}$ to $1 \mathrm{~cm}$ in both groups. A total

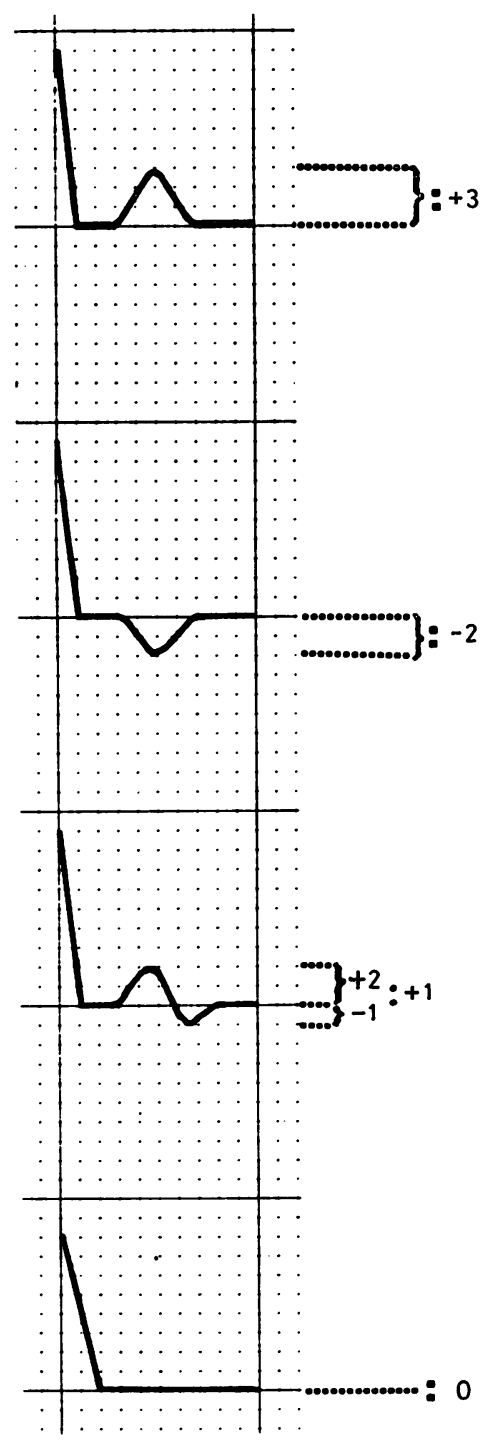

Fig. 1 The maximum magnitude of the $T$-wave above or below the baseline was measured and recorded as positive or negative $(1 \mathrm{~mm}=0.1 \mathrm{mV})$. The net of diphasic $T$-wave was calculated as shown in the third panel.
Table Arbitrary electrocardiographic criteria of myocardial ischaemia in the newborn

\begin{tabular}{|c|c|c|c|}
\hline Grade 1 & Grade 2 & Grade 3 & Grade 4 \\
\hline $\begin{array}{l}\text { T-wave flat or } \\
\text { inverted in } 1 \\
\text { or } 2 \text { leads } \\
\text { (except } \\
\text { AVR) }\end{array}$ & $\begin{array}{l}\text { T-wave flat or } \\
\text { inverted in }>3 \\
\text { leads (except } \\
\text { AVR) }\end{array}$ & $\begin{array}{l}\text { T-wave flat or } \\
\text { inverted in } \\
>3 \text { leads } \\
\text { (except AVR) } \\
\text { and either }\end{array}$ & $\begin{array}{l}\text { Classical } \\
\text { segmental } \\
\text { infarction with } \\
\text { abnormal } \\
\text { Q-wave and } \\
\text { markedly } \\
\text { raised ST }\end{array}$ \\
\hline $\begin{array}{l}\text { Normal ST } \\
\text { segments }\end{array}$ & $\begin{array}{l}\text { Normal ST } \\
\text { segments }\end{array}$ & $\begin{array}{l}\text { ST depression } \\
\text { or elevation } \\
>2 \mathrm{~mm} \text { in at } \\
\text { least } 2 \text { chest }\end{array}$ & $\begin{array}{l}\text { segments or } \\
\text { complete left } \\
\text { bundle branch } \\
\text { block }\end{array}$ \\
\hline $\begin{array}{l}\text { Normal Q } \\
\text { waves }\end{array}$ & $\begin{array}{l}\text { Normal } \\
Q \text { waves }\end{array}$ & $\begin{array}{l}\text { leads or }>1 \mathrm{~mm} \\
\text { in at least } 2 \\
\text { standard leads } \\
\text { or } \\
\text { Q-wave abnor- } \\
\text { mality defined as } \\
\text { duration }>0.02 \\
\text { seconds or } \\
\text { amplitude }>25 \% \\
R \text { wave, in } 1 \\
\text { anterior or } 3 \\
\text { related chest } \\
\text { leads }\end{array}$ & \\
\hline
\end{tabular}

of 117 ECGs were obtained from 44 healthy newborn infants and 45 from 17 stressed neonates. All ECGs were analysed for:

1) T-wave axis in the horizontal and frontal planes.

2) T-wave amplitude in leads I, II, III, aVL, aVF, and V1-6.

3) Serial changes in T-wave amplitude.

The mean $\mathrm{T}$-wave axis in the horizontal and frontal planes was determined using Bayley's hexaxial references frame. ${ }^{11}$ In the horizontal plane we used $\mathrm{V} 2$ and V5 for the $\mathrm{Z}$ and $\mathrm{X}$ axes as they are nearly perpendicular to each other. ${ }^{12}$ Fig. 1 shows a model for measurement of T-wave amplitude. We also developed arbitrary criteria to define electrical evidence of myocardial ischaemia in the newborn (Table).

Statistical analysis. Because of the nature of the angular data specific calculations were used to determine the mean angle of the T-wave axis in each time period..$^{13}$ To define significant differences between the healthy and stressed groups, the Watson and William's 2 sample test was used to compare 2 circular samples. ${ }^{14} \mathrm{~A}$ value of $\mathrm{P} \leqslant 0.05$ was considered statistically significant.

\section{Results}

Distribution of the mean frontal $T$-wave axis calculated for healthy and stressed infants at 5 to 8 hours (time period 1), 24 to 33 hours (time period 2), 
and 71 to 96 hours (time period 3) after delivery are shown in Fig. 2 (a) and (b). There is a progressive leftward shift of the vector throughout the period of observation in both groups, although the shift lags in time period 2 in stressed babies. The distribution of mean horizontal $\mathrm{T}$-wave axis calculated for healthy and stressed infants for the same time periods after delivery is shown in Fig. 3 (a) and (b). There is a shift of the T-wave vector from anterior and leftward in both groups to leftward and posterior in the healthy babies and less posterior orientation in distressed babies. An important difference was found between the healthy and stressed groups when comparing the frontal plane $T$-wave axis at time period 2 but no other statistically significant differences were found.

T-wave amplitude. Serial $T$-wave amplitude changes are shown in Fig. 4 (a) and (b). In most babies in both

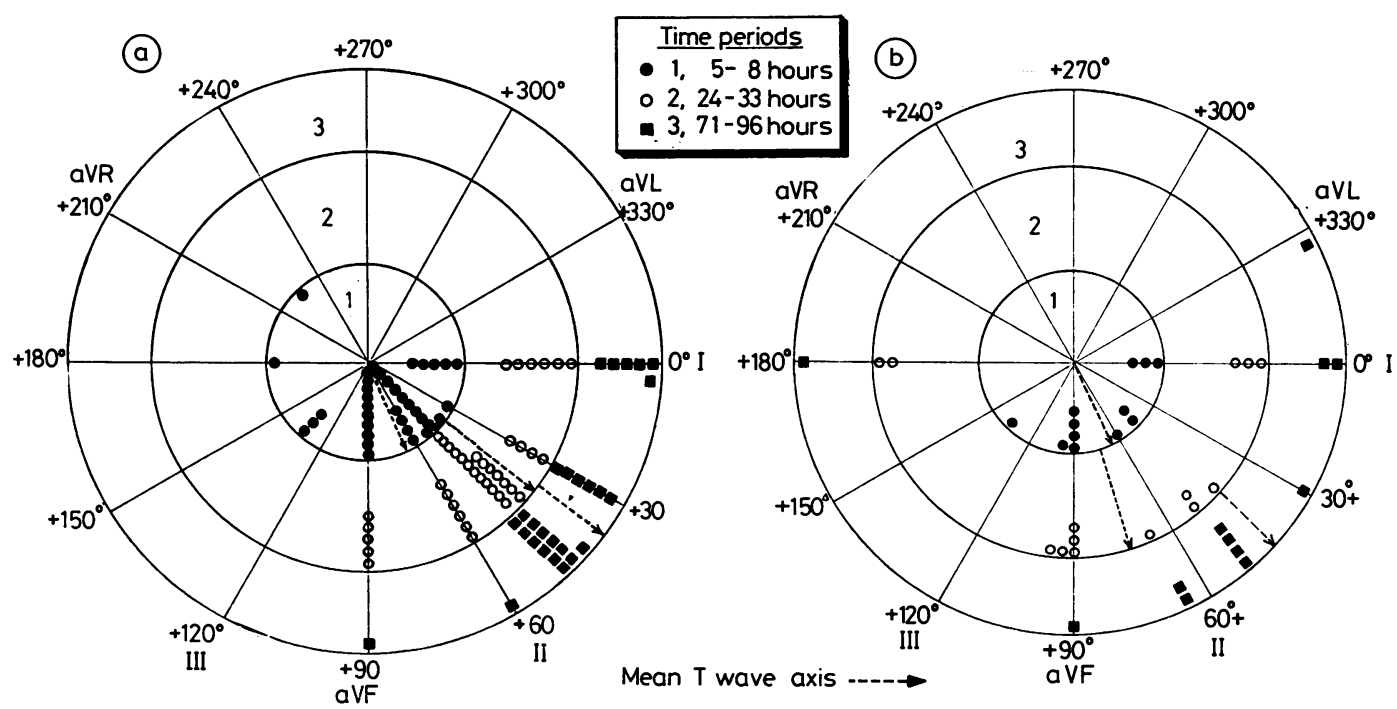

Fig. 2 Frontal plane T-wave axis in (a) healthy neonates and (b) stressed neonates.

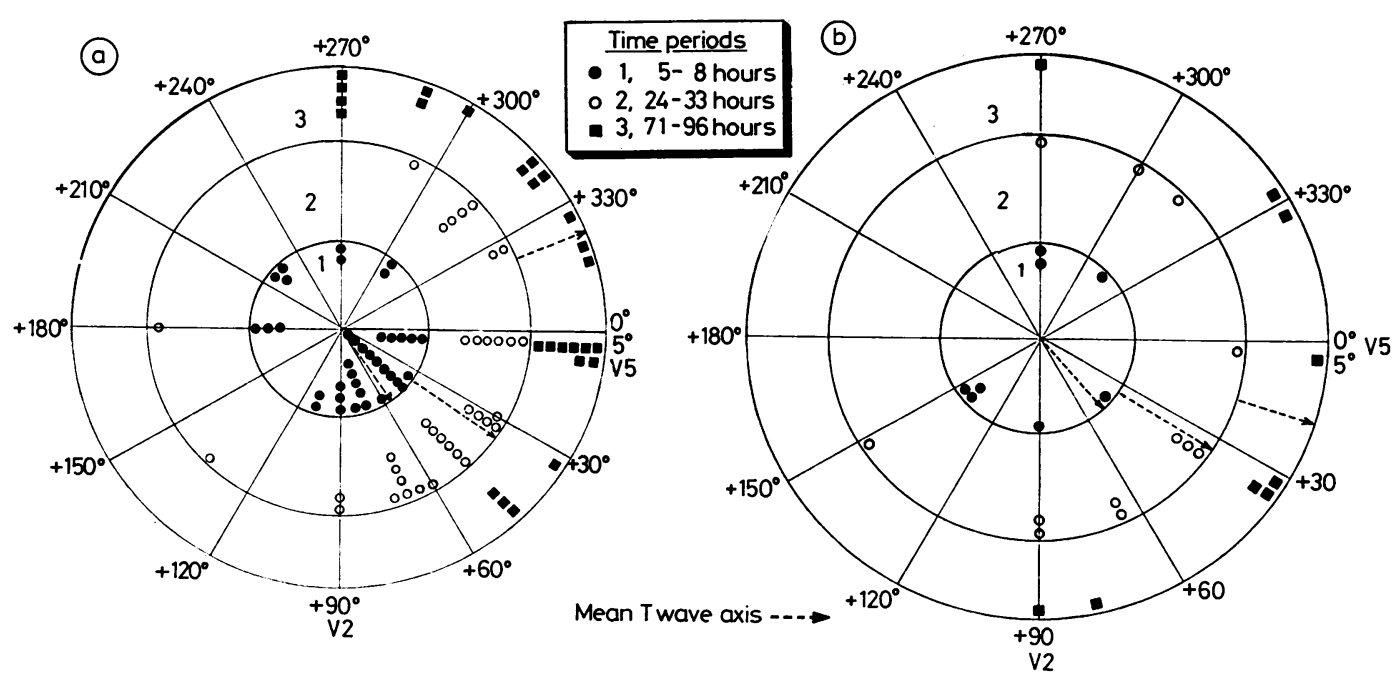

Fig. 3 Horizontal plane T-wave axis in (a) healthy neonates and (b) stressed neonates. 


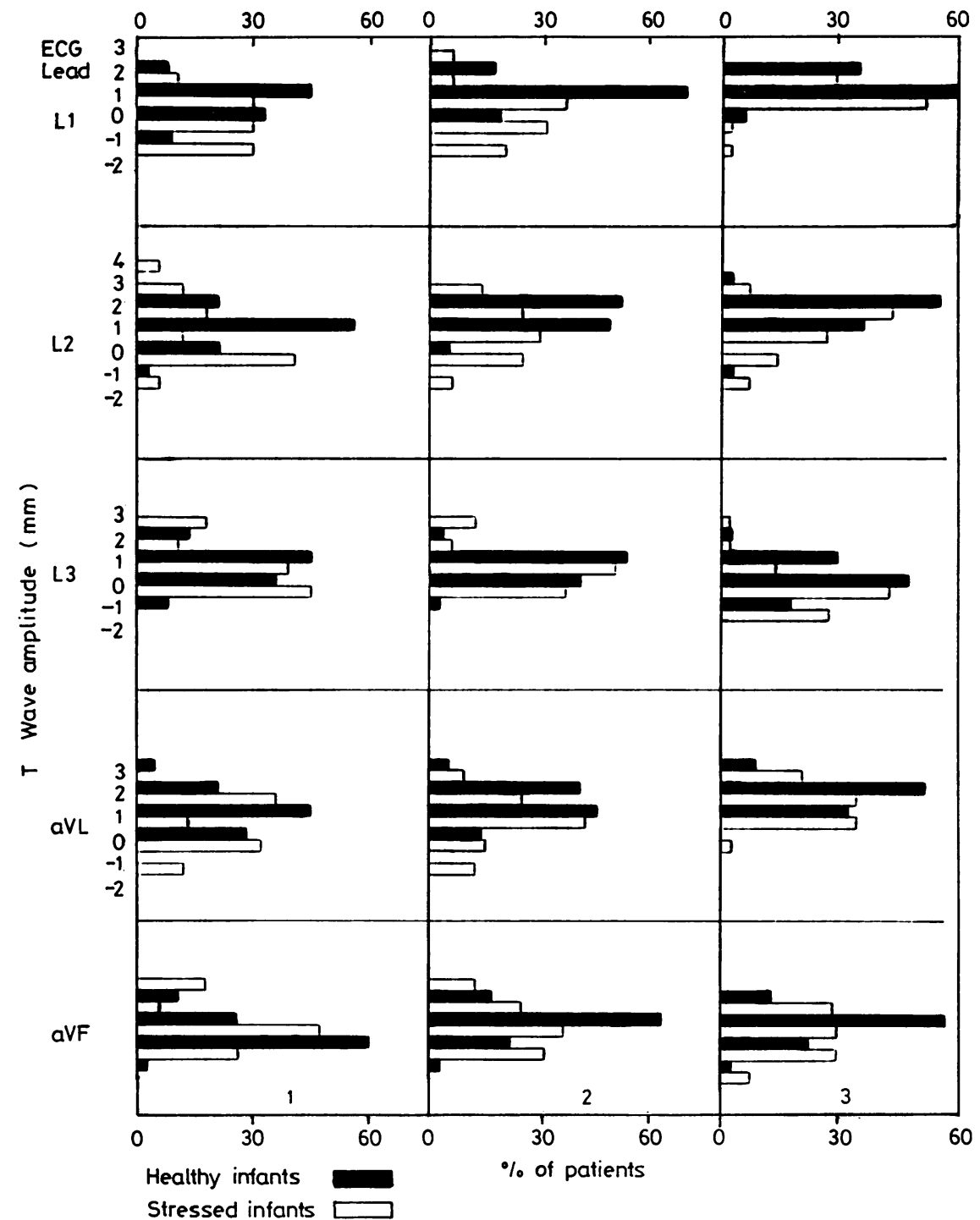

Fig. 4 (a) Frequency distribution of $T$-wave amplitude in serial electrocardiograms in healthy and stressed newborns.

groups low amplitude or inverted T-waves were observed soon after birth in the standard and precordial leads selected for study. Serial increases in T-wave amplitude were noted in all leads over the next few days except in leads III, aVF, V1, and V2 in which a decrease in amplitude or inversion of the $\mathrm{T}$-wave evolved. In the stressed infants $T$-waves in the right precordial leads remained more positive than in the healthy newborn. By 71 to 96 hours of age the T-waves in the right precordial leads were appreciably less inverted in the stressed than in healthy infants.
In lead I and aVL the T-wave amplitude was greater in healthy babies. By 24 hours a T-wave of zero value or negative in leads I and II was a much more common finding in stressed than in healthy babies. Differences in $\mathrm{T}$-waves in left precordial leads did not show important differences between the 2 groups.

Ischaemic ECG scores. Using the arbitrary criteria from the Table no difference was found between the 2 groups of infants. In the healthy group, an improve- 


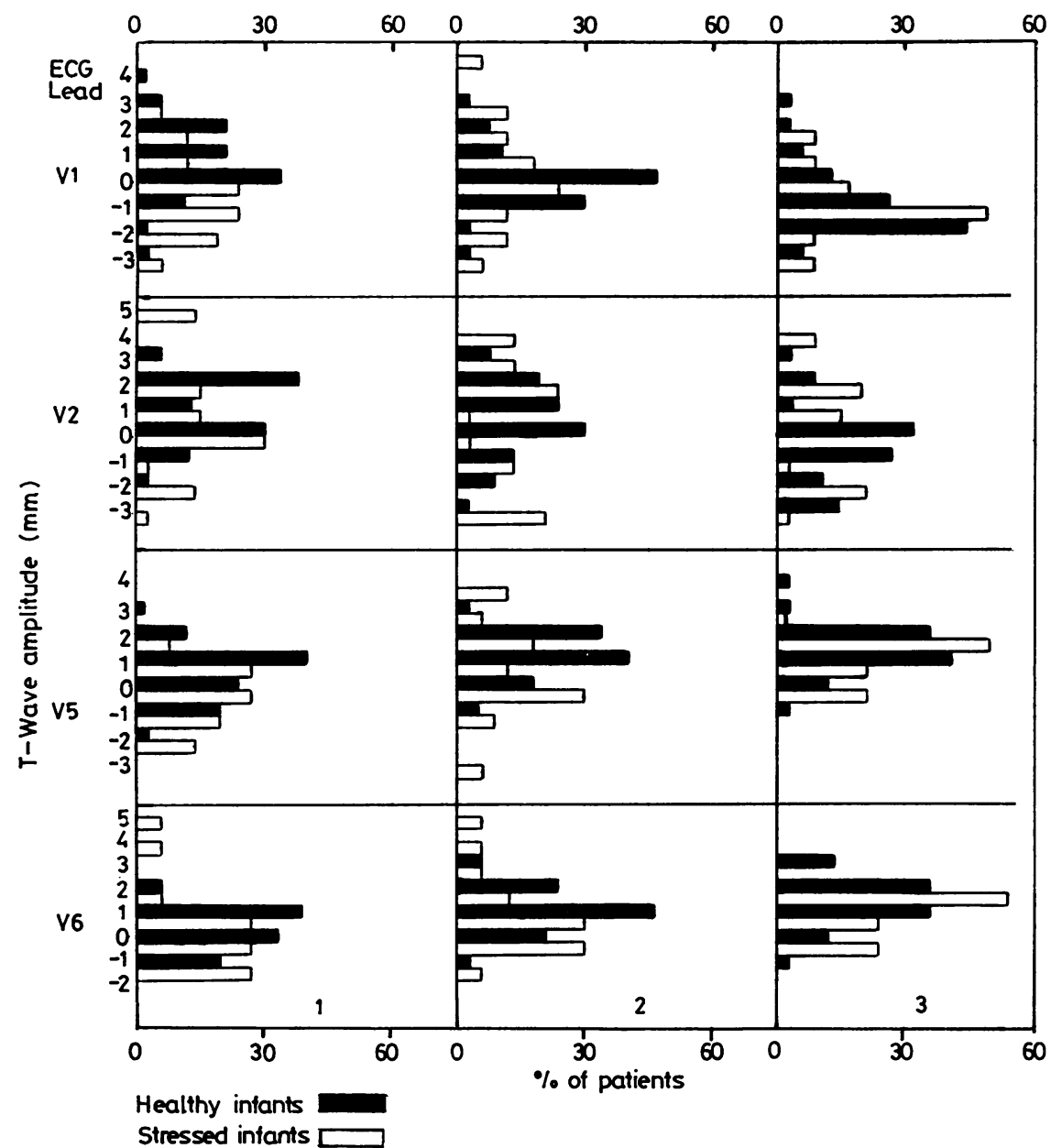

Fig. 4 (b) Frequency distribution of T-wave amplitude in serial electrocardiograms in healthy and stressed newborns.

ment in the mean ischaemic grade was noted by 71 to 96 hours of age and a similar but more gradual trend was noted in the group in whom higher grades of ischaemia occurred (Fig. 5).

\section{Discussion}

It has been known for many years that the $\mathrm{T}$-axis in the ECG of term infants undergoes striking changes during the first few days of life. The T-vector begins to alter direction within minutes of delivery ${ }^{125}$ and its peak alteration is reached between the ages of 2 and 6 hours. $^{12}$ In scalar records this implies that while the T-wave is upright in lead $\mathrm{I}, \mathrm{aVL}$, and in both extremities of the precordial leads at birth, $\mathrm{T}$-waves become inverted in lead I, aVL, and V6 shortly theraefter. The T becomes upright in leads I, II, aVF, and V6 during the latter part of the first day or over the next few days. Our experience and current studies show that the T-wave is positive in limb leads (particularly in leads I and II) in most healthy babies by 24 hours of age. The present study shows that $\mathrm{T}$-wave changes observed between 5 and 8 hours of age in babies who were hypoxic at birth may be similar to those seen in the healthy infants of the same age. This might be expected in a sample of infants with birth asphyxia varying from mild to marked severity. There is, however, a definite trend for the restitution phase of 


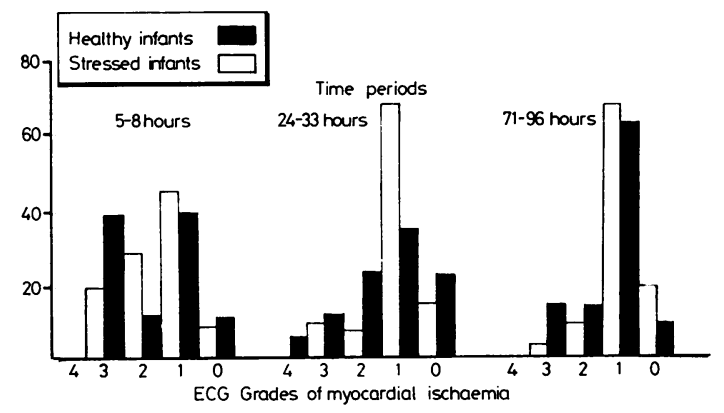

Fig. 5 Frequency distribution of electrocardiographic (ECG) grades of myocardial ischaemia in healthy and stressed newborns. 1, 2, and 3 represent electrocardiograms taken at 5 to 8 hours, 24 to 33 hours, and 71 to 96 hours after birth. (See Table 1 for ECG grades).

the T-axis to be delayed for as long as 72 to 96 hours in stressed infants. This is seen especially in the horizontal plane at 71 to 96 hours. If T-waves are flat or negative in leads I and II at or after 24 hours of age it is probable that the ECG shows an abnormality and that there is myocardial damage. Since quantitative changes in the $\mathrm{T}$-waves were examined in a limited way only in our study we cannot say whether a sum of the polarity in standard leads (equivalent to the overall visual impression of the ECG) might be a more sensitive index of abnormality. ${ }^{10}$

More convincing evidence of ischaemic damage emerges when changes additional to $\mathrm{T}$-wave alterations are examined (Table). If our grade 3 or 4 criteria are used as ECG indicators of myocardial ischaemic damage stressed infants have abnormalities twice as often as healthy babies at 5 to 8 hours, 22 to 48 hours, and 71 to 96 hours after delivery. A conclusive diagnosis of myocardial necrosis may be made only by histological examination of the heart in infants who die after 24 hours of age. Most babies with a clinical picture of myocardial ischaemic damage at birth survive so that it is difficult to determine which have true and false positive and which have true and false negative ECGs. Specificity and sensitivity for that test are thus uncertain. Assuming that abnormal ECGs (grade 3 or 4 changes) in healthy babies represent false positive tests and that all ill babies who do not have such changes represent false negative tests (neither of which is necessarily true), the sensitivity of the ECG as a detector of myocardial ischaemic damage at 5 to 8 hours is only $40 \%$ and the specificity is $81 \%$. Using the same assumption for healthy and ill babies, but taking the $\mathrm{T}$-wave as having zero or negative amplitude in lead II at 24 hours rather than arbitrary grades as indicative of myocardial ischaemic damage, the sensitivity is relatively poor $(30 \%)$ and specificity is $96 \%$.

-In an earlier retrospective blind study of the ECG and myocardial histology (where sections were technically adequate) in 14 infants with birth asphyxia who died at age over 30 hours after delivery, Dische et al. found the ECG highly sensitive and specific-they found 13 true positive and 1 true negative ECG. ${ }^{15}$ In that study 7 of 14 patients in whom the histology showed varying degrees of myocardial damage ( 3 moderate to severe in extent) had ECG changes corresponding closely to the grade 2 criteria for ischaemia used in the present study. These patients were all older than 24 hours (a fact that lends further support to our findings) suggesting that the diagnosis of true ischaemic damage is more apparent after the first day of life.

It appears that ECG changes, even of a degree that would indicate myocardial damage in older children, are not sufficiently sensitive in the first 12 hours to predict which infants will have abnormal ECG tracings at 24 hours of age - the time when the ECG diagnosis of ischaemia can be made with much greater authority. Although haemodynamic events in the first few hours after birth ${ }^{16}$ suggest that the normal left ventricle may undergo sufficient haemodynamic stress to produce transient subendocardial ischaemia, it has been difficult to obtain proof of a change which is much more subtle than that seen in stressed infants.

Many factors, including electrolyte and calcium imbalance and acidosis, can cause alterations in T-waves and occasionally in ST segments. Other more difficult avenues are being explored in animal experimentation but for the present, in humans, the tantalising question posed earlier by Hait and Gasul ${ }^{1}$ of whether transient subendocardial ischaemia occurs normally after birth remains unanswered.

We conclude that assessment of $\mathrm{T}$-wave axis alone as a function of myocardial ischaemia in term infants is reliable only after 24 hours of age. Suspicion of myocardial ischaemic damage may reasonably be entertained during the first day of life when ST segment shifts or abnormal Q-waves exist in addition. Unfortunately, more convincing ECG evidence of myocardial ischaemia-left bundle branch block or frank segmental infarction patterns-are so uncommon as to have limited value in diagnosis of ischaemic damage in stressed infants.

We are grateful for the expert statistical assistance of David Cook in preparing this article. This study was supported by a grant from Pediatric Consultants of the Hospital for Sick Children, Toronto. 


\section{References}

1 Hait G, Gasul BM. The evolution and significance of $T$-wave changes in the normal newborn during the first seven days of life. Am J Cardiol 1963; 12: 494-504.

2 Rothfeld EL, Wachtel FW, Karlen WS, Bernstein A. The evolution of the vectorcardiogram and electrocardiogram of the normal infant. I The normal newborn. Am J Cardiol $1960 ; 5$ : 439-49.

3 Depasquale NP, Burch GE. The electrocardiogram, ventricular gradient and spatial vectorcardiogram during the first week of life. Am J Cardiol 1963; 12: 482-93.

4 Scott O, Franklin D. The electrocardiogram in the normal infant. Br Heart J 1963; 25 : 441-50.

5 Ziegler RF. The importance of positive T-waves in the right precordial electrocardiogram during the first year of life. Am Heart J 1956; 52 : 533-46.

6 Rowe RD, Hoffman T. Transient myocardial ischemia of the newborn infant: a form of severe cardiorespiratory distress in full-term infants. $J$ Pediatr $1972 ; 81$ : 243-50.

7 Ahvenainen ED, Landtman B. Asphyxia neonatorum and electrocardiographic and post mortem studies. Annales Medicinae Internae Fenniae (Helsinki) 1954; 43: 1-24.

8 Hori H, Imai M, and Sato M. On the electrocardiogram of the newborn. Second Report on the Electrocardiogram of the Asphyxiated Newborn. Jpn J Obs \& Gyn 1935; 18: 333-9.

9 Bucciarelli RL, Nelson RM, Egan EA, Eitzman DV, Gessner IH. Transient tricuspid insufficiency of the newborn: a form of myocardial dysfunction in stressed newborns. Pediatrics 1977; 59: 330-7.
10 Rowe RD. Myocardial ischaemia in the newborn. In: Godman MJK, Marquis RM, eds. Paediatric cardiology, 1978: heart disease in the neonate. Edinburgh: Churchill Livingstone, 1979.

11 Bayley RH. On certain applications of modern electrocardiographic theory to the interpretation of electrocardiograms which indicate myocardial disease. Am Heart J 1943; 26: 769-831.

12 Lamb LE. Electrocardiography and vectorcardiography. Philadelphia: WB Saunders, 1965.

13 Mardia KV. Statistics of directional data. London and New York: Academic Press, 1972: 18-28.

14 Mardia KV. Statistics of directional data. London and New York: Academic Press, 1972: 152-6.

15 Dische MR, Jimenez CC, Freedom RM, et al. Effects of perinatal hypoxia on the infantile heart: Interim Meeting Am Ped Path Club. Long Beach, California (abstract), 1977.

16 Rudolph AM. The changes in the circulation after birth: their importance in congenital heart disease. Circulation $1970 ; 41$ : 343-59.

Correspondence to Richard D Rowe, Division of Cardiology, The Hospital for Sick Children, 555 University Avenue, Toronto, Ontario, M5G 1X8 Canada.

Received 15 April 1983 